\title{
Autologous Cytotoxic T-lymphocytes Exposed to Dendritic Cells loaded with 6B11 Anti-idiotype Minibody
}

National Cancer Institute

\section{Source}

National Cancer Institute. Autologous Cytotoxic T-lymphocytes Exposed to Dendritic

Cells loaded with 6B11 Anti-idiotype Minibody. NCI Thesaurus. Code C158601.

A preparation of autologous cytotoxic T-lymphocytes (CT Ls) that are exposed, ex vivo, to autologous dendritic cells (DCs) loaded with the anti-idiotype minibody 6B11, which mimics the epithelial ovarian tumor-associated antigen (TAA), OC166-9, with potential immunostimulatory and antineoplastic activities. Upon administration, the CT Ls exposed to DCs loaded with 6B11 anti-idiotype minibody target and kill autologous ovarian cells expressing the TAA. 